The traditional blame attached, by many clinicians, to the endocrine system in the causation of obesity was repudiated by Dr. Raymond Greene (London) in "The Effects of the Endocrine System on Calorie Balance in Man". The several endocrine glands were considered in brief, abnormalities of some of them being associated with modifications in the water content of the body; occasionally obesity occurs concomitantly with endocrine pathology but rarely, he thought, is hormonal disorder of any great importance. Dr. Greene suggested that a more interesting discourse, rather than the prescribed one, might have been on "the influence of nutrition on the endocrine system".

Within recent years some changes in outlook on the nature of fat metabolism have been apparent. It has been suggested, although not always with convincing experimental evidence, that the fat depots of the body are far from inactive tissues and indeed are continuously being mobilized. Their nerve supply is stated to be extensive, although most histologists appear to have some difficulty in finding many nerve endings, as opposed to nerve fibres, in adipose tissue. Prof. A. Kekwick and his colleagues have been engaged in studying the "Metabolism of Adipose Tissue", the subject of a paper by Dr. T. M. Chalmers (Middlesex Hospital, London). $\mathrm{H}_{\theta}$ suggested that free fatty acid and not glucose might be the principal energy substrate, because of its rapid turnover in the plasma. The fat-mobilizing substance, found in the urine of fasting men, might have some physiological role; its release in the urine apparently depends on carbohydrate metabolism, this being demonstrated in one obese patient treated with equicalorific diets containing varying amounts of carbohydrate.

The second half of the meeting began with a paper on "Energy Expenditure and Calorie Intake in Young Men" by Dr. O. G. Edholm (Medical Research Council, London). In a series of 6 surveys, on 54 Army recruits, he had found variations in energy expenditure of from 2,200 to 6,100 kealories/day and of intake from 671 to $8,750 \mathrm{kcalories} / \mathrm{day}$, with means of about 3,800. The lack of agreement between calorie balance and the weight balance of the body was again stressed, when these were measured over periods of a few days. There is not sufficient information at present to determine the effect, if any, of severe cold on calorie balance. Work carried out in the Antarctic has shown that men put on weight in the winter and lose weight in the summer; this might be due to climatological factors, but equally well might reflect different social circumstances.

The amount and the rationale of the extra "Calorie Requirements in Pregnancy" were discussed by Dr. A. M. Thomson and Dr. F. Hytten (University of Aberdeen). From a series of several hundred healthy primiparæ studied in Aberdeen, it seemed that an average of about $4 \mathrm{kgm}$. of fat was added to the mother's tissues by the time pregnancy ended. This is almost certainly physiological, and is required to help the mother in the needs of lactation ; however, if breast-feeding is becoming much less common, as appears to be true in Western society, this extra gain in weight may predispose to future obesity. The authors emphasized the small amount of experimental information on the exact increase in food taken during pregnancy and the degree of the changes, if any at all, in the amount of physical activity of the woman; this has a considerable bearing on any extra allowance recommended.

From the interesting paper by Dr. E. M. Widdowson (University of Cambridge) on "Energy Balance in Early Life", new-born babies are frequently subjected to considerable stress by deprivation of food. When this happens, the fat stores of the body are quickly used up, particularly if the baby is required to maintain a high metabolic rate. This will be necessary if the environmental temperature does not fall within the critical range $32-35^{\circ} \mathrm{C}$. Babies appear to be as variable in their energy expenditure as adults, and it seems unphysiological to expect all babies to require similar quantities of food.

The discussion of the papers was relevant, interesting and prolonged; the meeting was a most successful one.
J. V. G. A. Durnin

\title{
WATER IN AUSTRALIA
}

$\mathrm{M}$ AN'S existence depends on an adequate supply of water, and in Australia, as in few other countries, future development will depend on using water resources to the full. An important step in the utilization of water is the understanding of its properties, and the Victorian Branch of the Royal Australian Chemical Institute found no difficulty in attracting some fifty sciontists from four Australian States, whose interests ranged from engineering to biology, to a three-day discussion on this broad topic. The meeting was hold at Warburton, Victoria, in late November.

In the opening talk Dr. J. A. Barker reviewod the structure of hydrates and of ice as an introduction to the loosely packed structure of liquid water in which the molecules are prevented from coming into closest proximity by tetrahedrally arranged hydrogen bonds. Each pattern of hydrogen bonds persists for periods of the order of $10^{-12}$ sec. The theory of Pople, based on this picture, would require each water molecule to have 4 nearest neighbours, 12 next nearest and 36 third nearest, whereas the correspond- ing figures obtained from analysis of $\mathrm{X}$-ray diffraction data are 4, 11 and 22 . Dr. Barker contrasted the anomalous properties of water that result from this structure-the decrease in solubility of gases with increasing temperature, the high negative temperature coefficient of viscosity - with the properties of more normal liquids in which the molecules are closely packed.

Evidence consistent with this structure was presented by Dr. S. D. Hamann, who described some of the effects of pressure on the proporties of water and showed how many of the anomalies disappear as the moloculos become close-packed at pressures greator than 2,000 atm. Thus with increasing pressure the thermal expansion of water became 'normal', its sound absorption decreased as pressure broke down its structure, and its dielectric constant decreased. Measurements of the conductivity of water under pressures up to $130,000 \mathrm{~atm}$. had produced increases in ionization so that its conductivity equals that of a $5-N$ solution of hydrochloric acid. Pressures of this order are probably reached at depths of $400 \mathrm{~km}$. in 
the Earth and the enhanced ionization therefore has interesting geophysical implications.

Dr. P. W. Posener showed how microwave spectroscopy could be used to fill in details in the above broad picture.

Considerations of the electronegativity of the oxygen atom in water and hydrates, in both the normal and excited states, led Dr. J. F. Duncan to certain novel and controversial generalizations on the oxidation properties of water. Subjects as diverse as the thermodynamic properties of aqueous ions, the radiolysis of water and the kinetics of aquation reactions could be described semi-quantitatively.

Prof. R. C. L. Bosworth reminded the meeting of the experiments of Nukiyama on the boiling of water, first described in 1934 but disregarded for some fifteen years. A study of boiling produced by a heated platinum wire immersed in water, relating the heat input to the temperature of the wire, revealed three distinct zones of boiling, sometimes with discontinuities between them. The phenomena described by Prof. Bosworth clearly have important practical implications for the design of boilers and heat exchangers. Dr. K. L. Sutherland suggested in discussion that the variation of contact angle with applied potential that had been observed by Frumkin could perhaps be used in controlling boiling. By causing an applied potential to fluctuate at a predetermined rate it might be possible to alternate the periods of bubble formation (large contact angle) with those of bubble release (zero contact angle).

Dr. G. F. Walker described some vermiculitebutyl ammonium ion complexes, their swelling in water, and the intriguing behaviour of their swollen forms. The $10-\AA$. thick silicate layers, $4 \mathrm{~mm} .^{2}$ in area, remained parallel to each other even at interlayer spacings up to $600 \AA$. The interlayer spacing depended on the concentration and type of cations present and could be varied reversibly under the influence of an electric potential. The phenomenon lacks, as yet, a full theoretical explanation and may have novel applications as a variable molecular sieve.

"Water in Australia" was the topic chosen by Mr. L. R. East in opening the part of the meeting that dealt with conservation. Conservation in Australia poses special problems; an average rainfall of $16 \cdot 5 \mathrm{in}$. compared with the average of 26 in. for all land masses, the large area and small population, and the combined influence of the great variations of rainfall in good and bad years - and of the disastrous reduction of the proportion of rain-water finding its way into the rivers in years of drought. He contrasted the lack of a national water policy in Australia, in spite of significant nineteenth-century contributions, with that initiated in the United States by Theodore Roosevelt in 1901 , when he stated that "The reclamation and settlement of arid lands will enrich every portion of our country. ...".

Mr. East discounted the possibility of affecting the climate of neighbouring areas by constructing large inland dams. In this he was supported by Dr. C. H. B. Priestley, who said that, although man had undoubtedly affected weather by his clearing and cultivation of millions of square miles, localized activities were unlikely to have an appreciable effect. He used measurements made over the Mississippi basin to illustrate the balance of water in the atmosphere and showed that up to 90 per cent of the rainfall came from maritime air and only about 10 per cent from continental air.
Mr. E. J. Smith brought the meeting up to date on the progress of rain-making research in Sydney, and pointed out the gaps which exist in the understanding of the nucleation process. In particular, he stressed the possible importance of the particle size of the nuclei as it affected their ability to promote iceformation and their decay by photolysis and other mechanisms.

Advances in evaporation control with cetyl alcohol were described by Mr. W. W. Mansfield. For large areas of water the alcohol is dusted on to the surface by a grinder-duster, and from the particles a film spreads over the surface. Evaporation, under ideal circumstances, can be reduced by as much as 40 per cent, but the method becomes much less effective as the wind velocity increases. The cost, based on a test at Broken Hill, was one penny per thousand gallons saved.

Two methods of reducing the salt content of water were described by Messrs. R. B. Cooper and L. S. Herbert. Electrodialysis, described by Mr. Cooper, can be used economically to reduce the salt content of water from about 4-5,000 p.p.m. to 3-500 p.p.m. The power needed may be between 9 and $40 \mathrm{~kW} . \mathrm{hr}$./ 1,000 gallons, depending on the salt content and on the flow-rate required. Mr. Herbert discussed some aspects of the distillation of sea-water and suggested possible techniques to improve the efficiency of the process, particularly in increasing heat transfer coefficients. The theoretical minimum energy for any such process is about $3 \mathrm{~kW} . \mathrm{hr} . / 1,000$ gallons, but the practical minimum is about $12 \mathrm{~kW} . \mathrm{hr} . / 1,000$ gallons, a figure which is still far from realization. With known technology it should be possible, on a sufficiently large scale, to produce fresh water for $8 s$. per 1,000 gallons and eventually, with improvements in technique, to reduce this to about $4 s$. per 1,000 gallons.

Mr. J. W. Legge considered the physical-chemical properties of water in relation to the origin and evolution of life, and to L. J. Henderson's views on the fitness of the environment. Knowledge of film stability on natural water surfaces could throw light on current controversy about the kinetics of the synthesis of primitive proteins. He outlined current biochemical views of the splitting of water in photosynthesis and the recombination of hydrogen and oxygen in the aerobic cells.

The movement of water-solute through cell walls was related by Dr. L. R. Finch to the current picture of the membrane. The vesiculation observed in electron micrographs of thin sections, as well as the phenomenon of pinocytosis, involve, of necessity, changes in concentration at the interface. Accelerated metabolism of phospholipids could be shown to take place during such transport processes.

A good deal of discussion followed the contributions of Dr. J. R. Philip and Prof. J. H. Green, which were related to the theory and measurement of groundwater flow. Models for the process are complicated due to changes in the nature of the medium with water content, but Dr. Philip showed how they had been reduced to a tractable form by making use of the basic Navier-Stokes equations. Many were surprised by the high rates of ground-water movement which have been measured by observation of consciously and adventitiously added radioisotopes.

It is pleasing to report on a conference which aroused so much discussion, both formal and less so, and from which so many new patterns of collaboration promise to emerge. 